Supporting Information

For

\title{
Spectroscopic studies of the EutT adenosyltransferase from Salmonella enterica: Mechanism of four-coordinate Co(II)Cbl formation
}

Ivan. G. Pallares, Theodore. C. Moore, Jorge C. Escalante-Semerena, and Thomas C. Brunold

\section{CONTENTS}

Details about Sample Compositions. Information regarding the compositions of all samples used in this study.

Table S1. Detailed compositions of the samples used to obtain the spectra presented in the main text.

Table S2. Detailed compositions of the samples used to obtain the spectra presented in the supporting information.

Figure S1. Low-temperature Abs and MCD spectra of $\mathrm{Co}(\mathrm{II}) \mathrm{Cbl}$ under anaerobic conditions and in the presence of $\mathrm{EutT}^{\mathrm{WT}} / \mathrm{Fe}(\mathrm{II})$ exposed to air.

Figure S2. Low-temperature MCD spectra of $\mathrm{Co}(\mathrm{II}) \mathrm{Cbl}$ in the presence of $\mathrm{EutT}^{\mathrm{WT}} / \mathrm{Zn}(\mathrm{II})$ or EutT $^{\mathrm{WT}} / \mathrm{Fe}(\mathrm{II})$ and a small or large amount of MgATP.

Figure S3. EPR spectra at $20 \mathrm{~K}$ of $\mathrm{Co}(\mathrm{II}) \mathrm{Cbl}$ in the presence of $\mathrm{EutT}^{\mathrm{WT}} / \mathrm{Zn}$ (II) or $\mathrm{EutT}^{\mathrm{WT}} / \mathrm{Fe}$ (II) and a small or large amount of MgATP.

Figure S4. EPR spectra at $40 \mathrm{~K}$ of $\mathrm{Co}(\mathrm{II}) \mathrm{Cbl}$ in the presence of $\mathrm{EutT}^{\mathrm{WT}} / \mathrm{Fe}, \mathrm{EutT}^{\mathrm{H} 65 \mathrm{~A}} / \mathrm{Fe}$, or EutT $^{\mathrm{H} 75 \mathrm{~A}} / \mathrm{Fe}$ and a $>3$-fold molar excess of MgATP.

Figure S5. Low-temperature MCD spectra of $\mathrm{Co}(\mathrm{II}) \mathrm{Cbl}$ in the presence of Eut $\mathrm{T}^{\mathrm{WT}} / \mathrm{Zn}$ under various conditions.

Figure S6. Low-temperature Abs and MCD spectra of EutT $\mathrm{T}^{\mathrm{WT}} / \mathrm{Fe}(\mathrm{II})$ in the absence of substrates.

Figure S7. Low-temperature Abs spectra of $\mathrm{Co}(\mathrm{II}) \mathrm{Cbl}$ in the presence of Eut $\mathrm{T}^{\mathrm{WT}} / \mathrm{Zn}, \mathrm{EutT}^{\mathrm{WT}} / \mathrm{Fe}$, and selected variants under various conditions.

Figure S8. Deconvolution of the MCD spectrum of $\mathrm{Co}(\mathrm{II}) \mathrm{Cbl}$ obtained in the presence of EutT $^{\mathrm{C} 79 \mathrm{~A}} / \mathrm{Fe}$ and a $>10$-fold molar excess of MgATP.

Figure S9. Deconvolution of the MCD spectrum of $\mathrm{Co}(\mathrm{II}) \mathrm{Cbl}$ obtained in the presence of Eut $^{\mathrm{H} 75 \mathrm{~A}} / \mathrm{Fe}$ and a 10 -fold molar excess of MgATP.

Figure S10. Deconvolution of the MCD spectrum of $\mathrm{Co}(\mathrm{II}) \mathrm{Cbl}$ obtained in the presence of EutT $^{\mathrm{H} 67 \mathrm{~A}} / \mathrm{Fe}$ and a $>10$-fold molar excess of MgATP. 
Details about Sample Compositions. Specific information about enzyme and Co(II)rrinoid preparations is provided in the main text. The concentrations of protein and $\mathrm{Co}(\mathrm{II})$ rrinoid species, protein/cofactor ratios, and glycerol contents for all samples used in this study are shown in Tables S1 and S2. Addition of Co(II)rrinoid substrate and further sample manipulations were performed inside an anaerobic glovebox. EPR samples were immedialte frozen in liquid nitrogen upon removal from the glovebox. Prior to freezing the samples for MCD experiments, electronic absorption spectra were collected at room temperature under a $\mathrm{N}_{2}$ atmosphere. A comparison of the absorpton spectra collected at room temperature and, subsequently, $4.5 \mathrm{~K}$ ruled out the formation of oxidized corrinoid species or significant structural changes to the corrinoid environment in response to freezing (Figure S7).

Table S1. Detailed compositions of the samples used to obtain the spectra presented in the main text, arranged by Figure number

\begin{tabular}{|c|c|c|c|c|c|c|c|c|}
\hline Figure & Trace & SeEutT Variant & $\begin{array}{l}\text { Protein } \\
(\mathrm{P}) / \mu \mathrm{M}\end{array}$ & $\begin{array}{l}\text { Corrinoid } \\
\text { (C) / } \mathrm{MM}\end{array}$ & $\begin{array}{l}\text { MgATP } \\
\text { (A) /mM }\end{array}$ & $\begin{array}{c}\mathrm{C}: \mathrm{P} \\
\text { Ratio }\end{array}$ & $\begin{array}{c}\text { ATP } \\
\text { Excess / } \\
\text { molar }\end{array}$ & $\begin{array}{c}\text { Glycerol } \\
\text { /(v:v) }\end{array}$ \\
\hline \multirow[t]{3}{*}{2} & A & WT & 156 & 118 & 2 & 0.76 & 13 & 0.52 \\
\hline & B & WT & 303 & 254 & 0 & 0.84 & 0.00 & 0.55 \\
\hline & C & $n / a$ & 0 & 300 & 0 & $n / a$ & $n / a$ & 0.60 \\
\hline \multirow[t]{5}{*}{3} & A & $n / a$ & 0 & 300 & 0 & $n / a$ & $n / a$ & 0.60 \\
\hline & B & WT & 319 & 237 & 0.01 & 0.74 & 0.03 & 0.55 \\
\hline & C & WT & 319 & 237 & 1 & 0.74 & 3.1 & 0.55 \\
\hline & D & WT & 319 & 237 & 5.7 & 0.74 & 18 & 0.55 \\
\hline & E & $n / a$ & 0 & 300 & 0 & $n / a$ & $n / a$ & 0.60 \\
\hline \multirow[t]{5}{*}{4,5} & A & $n / a$ & 0 & 300 & 0 & $n / a$ & $n / a$ & 0.60 \\
\hline & B & WT & 261 & 210 & 0.0075 & 0.80 & 0.03 & 0.55 \\
\hline & C & WT & 261 & 210 & 0.14 & 0.80 & 0.6 & 0.55 \\
\hline & D & WT & 261 & 210 & 0.28 & 0.80 & 1.07 & 0.55 \\
\hline & $E$ & WT & 319 & 237 & 5.7 & 0.74 & 18 & 0.55 \\
\hline \multirow[t]{5}{*}{6} & A & WT & 595 & 300 & 5 & 0.50 & 8.4 & 0.55 \\
\hline & B & WT & 397 & 280 & 8.1 & 0.71 & 20 & 0.65 \\
\hline & C & WT & 397 & 280 & 0.5 & 0.71 & 1.3 & 0.55 \\
\hline & D & WT & 595 & 300 & 0.003 & 0.50 & 0.01 & 0.55 \\
\hline & $E$ & $n / a$ & 0 & 300 & 0 & $n / a$ & $n / a$ & 0.60 \\
\hline \multirow[t]{8}{*}{7} & A & WT & 156 & 118 & 2 & 0.76 & 13 & 0.52 \\
\hline & B & C79A & 231 & 167 & 2.5 & 0.72 & 11 & 0.52 \\
\hline & C & $\mathrm{H} 75 \mathrm{~A}$ & 611 & 378 & 6 & 0.62 & 10 & 0.56 \\
\hline & D & H67A & 574 & 378 & 6 & 0.66 & 11 & 0.56 \\
\hline & $E$ & WT & 303 & 254 & 0 & 0.84 & 0.00 & 0.55 \\
\hline & $\mathrm{F}$ & $\mathrm{C} 80 \mathrm{~A}$ & 115 & 87 & 1.2 & 0.76 & 11 & 0.52 \\
\hline & G & C83A & 468 & 354 & 5.5 & 0.76 & 12 & 0.52 \\
\hline & $\mathrm{H}$ & none & 0 & 300 & 0 & $n / a$ & $n / a$ & 0.60 \\
\hline
\end{tabular}


Table S2. Detailed compositions of the samples used to obtain the spectra presented in the supporting information, arranged by Figure number

\begin{tabular}{|c|c|c|c|c|c|c|c|c|}
\hline Figure & Trace & SeEutT Variant & $\begin{array}{l}\text { Protein } \\
(\mathrm{P}) / \mu \mathrm{M}\end{array}$ & $\begin{array}{l}\text { Corrinoid } \\
\text { (C) } / \mu \mathrm{M}\end{array}$ & $\begin{array}{c}\text { MgATP } \\
\text { (A) } \\
/ \mathrm{mM}\end{array}$ & $\begin{array}{c}C: P \\
\text { Ratio }\end{array}$ & $\begin{array}{c}\text { ATP } \\
\text { Excess / } \\
\text { molar }\end{array}$ & $\begin{array}{c}\text { Glycerol } \\
\text { /(v:v) }\end{array}$ \\
\hline \multirow[t]{2}{*}{ S1 } & red & none & 0 & 300 & 0 & $n / a$ & $n / a$ & 0.60 \\
\hline & green & WT & 190 & 230 & 0.86 & 1.21 & 4.53 & 0.52 \\
\hline \multirow[t]{4}{*}{ S2 } & green (top) & WT & 156 & 118 & 2 & 0.76 & 12.82 & 0.52 \\
\hline & $\begin{array}{l}\text { green } \\
\text { (bottom) }\end{array}$ & WT & 303 & 254 & 0 & 0.84 & 0.00 & 0.55 \\
\hline & black (top) & WT & 595 & 300 & 5 & 0.50 & 8.40 & 0.55 \\
\hline & $\begin{array}{c}\text { black } \\
\text { (bottom) }\end{array}$ & WT & 595 & 300 & 0.003 & 0.50 & 0.01 & 0.55 \\
\hline \multirow[t]{4}{*}{ S3 } & green (top) & WT & 319 & 237 & 1 & 0.74 & 3.13 & 0.55 \\
\hline & $\begin{array}{l}\text { green } \\
\text { (bottom) }\end{array}$ & WT & 319 & 237 & 0.01 & 0.74 & 0.03 & 0.55 \\
\hline & black (top) & WT & 319 & 237 & 1 & 0.74 & 3.13 & 0.55 \\
\hline & $\begin{array}{c}\text { black } \\
\text { (bottom) }\end{array}$ & WT & 261 & 210 & 0.0075 & 0.80 & 0.03 & 0.55 \\
\hline \multirow[t]{3}{*}{ S4 } & blue & WT & 319 & 237 & 5.695 & 0.74 & 17.85 & 0.55 \\
\hline & green & H67A & 574 & 378 & 6 & 0.66 & 10.45 & 0.56 \\
\hline & light green & H75A & 611 & 378 & 6 & 0.62 & 9.82 & 0.56 \\
\hline \multirow[t]{3}{*}{ S5 } & red & $\begin{array}{c}\text { WT (1 mM } \\
\text { TCEP) }\end{array}$ & 595 & 300 & 5 & 0.50 & 8.40 & 0.55 \\
\hline & green & WT (no TCEP) & 595 & 300 & 5 & 0.50 & 8.40 & 0.55 \\
\hline & blue & WT & 595 & 300 & 0.003 & 0.50 & 0.01 & 0.55 \\
\hline S6 & all & WT & 198 & 0 & 2 & 0.00 & 10.10 & 0.60 \\
\hline S7 & Refer to Figur & & & & & & & \\
\hline
\end{tabular}




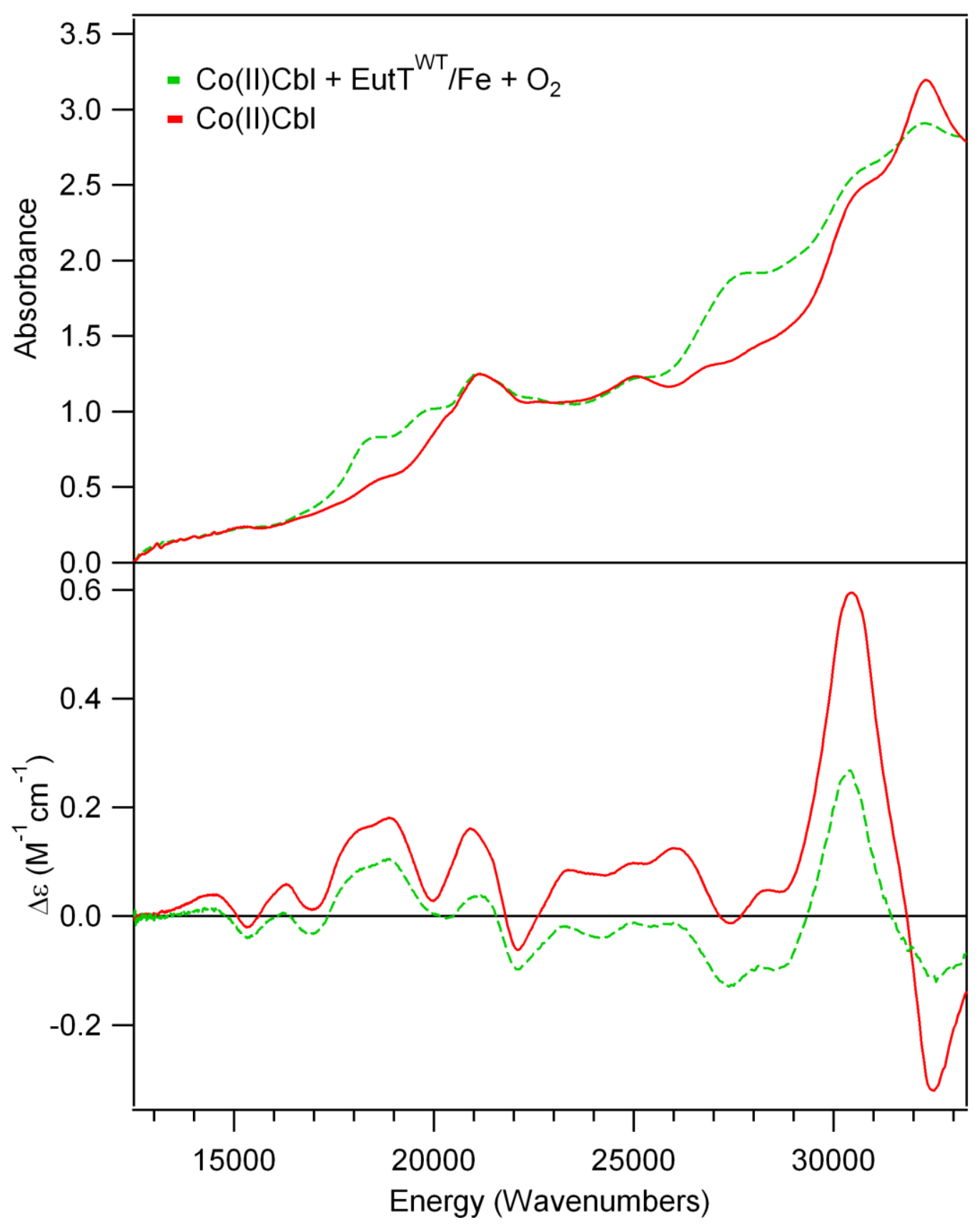

Figure S1. Low-temperature (4.5 K) Abs (top) and MCD (bottom) spectra of Co(II)Cbl in an anaerobic solution (red traces) and in the presence of $\mathrm{Eut}^{\mathrm{WT}} / \mathrm{Fe}(\mathrm{II})$ exposed to air (green traces). Spectroscopic changes observed at $19000 \mathrm{~cm}^{-1}$ and $28000 \mathrm{~cm}^{-1}$ in the Abs spectrum of $\mathrm{Co}(\mathrm{II}) \mathrm{Cbl}$ and $\mathrm{EutT}^{\mathrm{WT}} / \mathrm{Fe}$ (II) exposed to air are consistent with the formation of $\mathrm{H}_{2} \mathrm{OCbl}^{+}$due to oxidation of $\mathrm{Co}(\mathrm{II}) \mathrm{Cbl}$. 


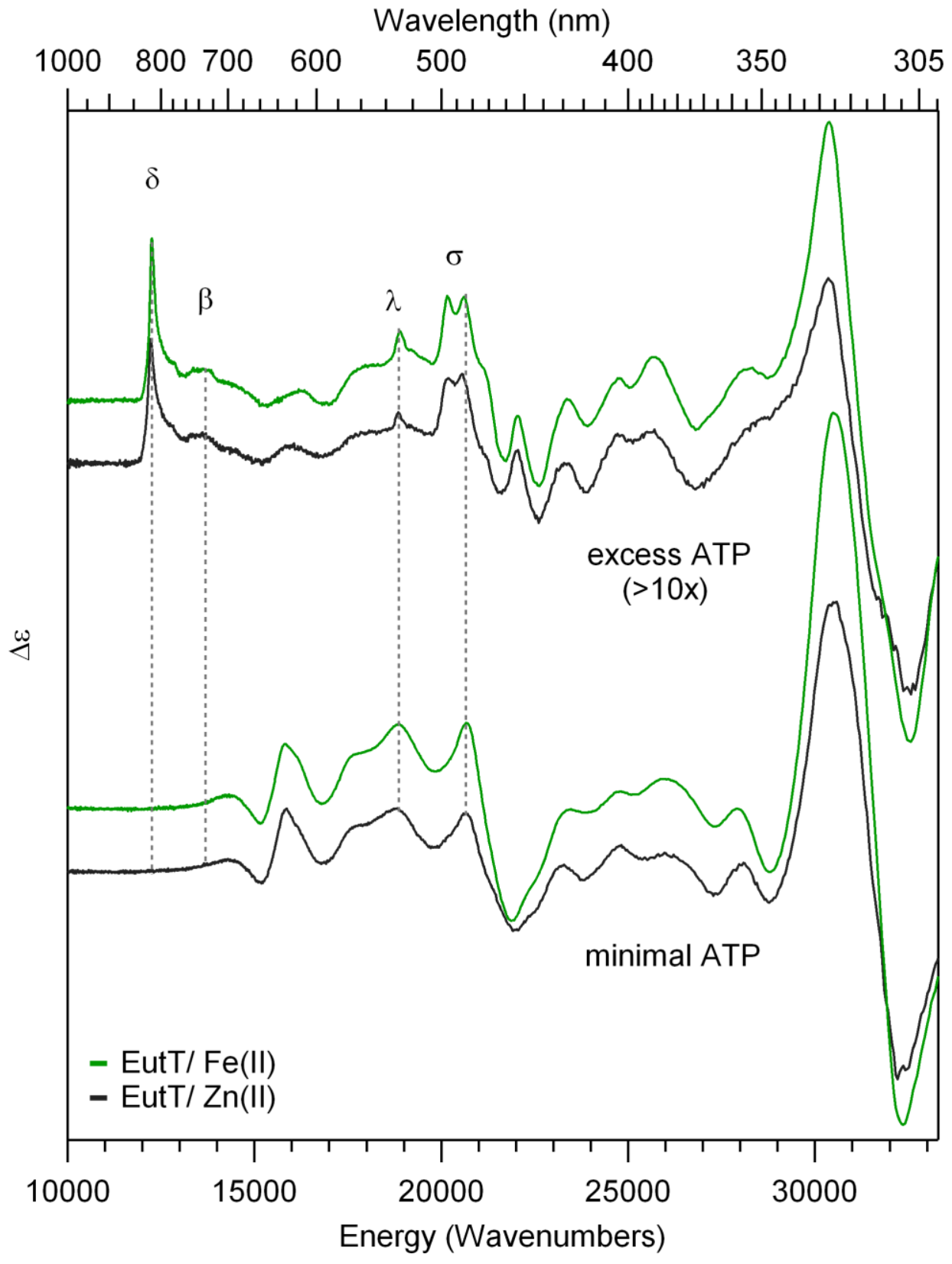

Figure S2. Low-temperature (4.5 K) MCD spectra of $\mathrm{Co}(\mathrm{II}) \mathrm{Cbl}$ obtained in the presence of Eut $^{\mathrm{WT}}$ purified in the presence of $\mathrm{Zn}$ (II) ions (black traces) or metallated with $\mathrm{Fe}(\mathrm{II})$ ions (green traces), and a $>10$-fold molar excess of MgATP (top) or substoichiometric ( $<10 \mu \mathrm{M}) \mathrm{MgATP}$ (bottom). The primary spectroscopic features due to $4 \mathrm{c} \mathrm{Co}(\mathrm{II}) \mathrm{Cbl}$ are labeled with Greek letters for the Fe-containing Eut $\mathrm{T}^{\mathrm{WT}}$ spectrum (top), and are highlighted with dotted vertical lines. 


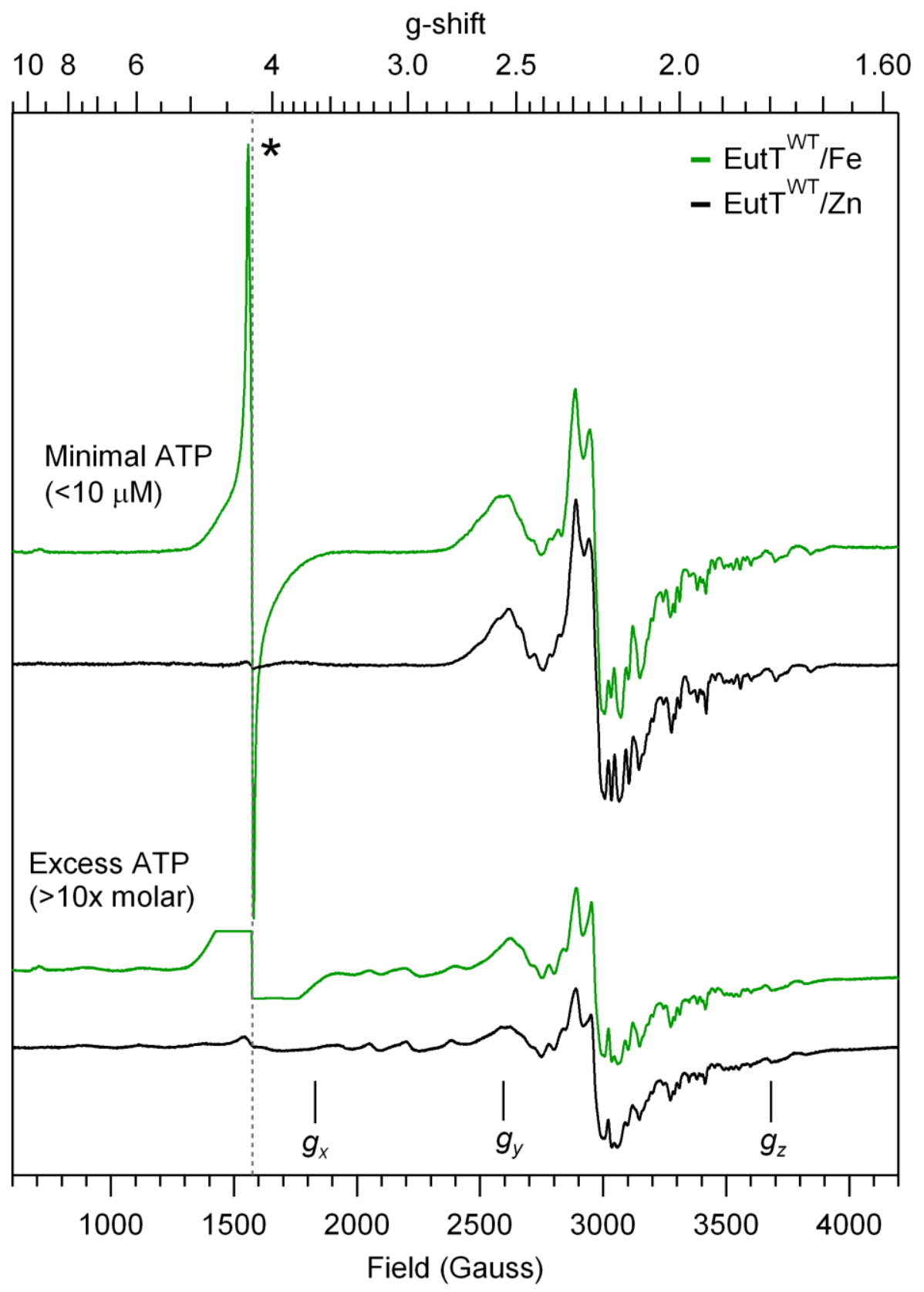

Figure S3. X-band EPR spectra collected at $20 \mathrm{~K}$ of free $\mathrm{Co}(\mathrm{II}) \mathrm{Cbl}$ in the presence of Eut $\mathrm{T}^{\mathrm{WT}} / \mathrm{Fe}$ (green traces) and Eut $\mathrm{T}^{\mathrm{WT}} / \mathrm{Zn}$ (black traces, in the presence of $<10 \mu \mathrm{M} \mathrm{MgATP}$ (top) or a ten-fold molar excess of MgATP (bottom). The field positions corresponding to the g-shifts from $4 \mathrm{c} \mathrm{Co(II)Cbl} \mathrm{species} \mathrm{are} \mathrm{labeled} \mathrm{in} \mathrm{the} \mathrm{spectrum}$ obtained in the presence of Eut $\mathrm{T}^{\mathrm{WT}} / \mathrm{Zn}$ and a ten-fold molar excess of MgATP. The feature asrising from ferric impurities is highlighted by an asterisk and a dashed vertical line. EPR spectra were collected using a $9.36 \mathrm{GHz}$ microwave source, $2 \mathrm{~mW}$ microwave power, $5 \mathrm{G}$ modulation amplitude, $100 \mathrm{kHz}$ modulation frequency, and a 328 ms time constant. 


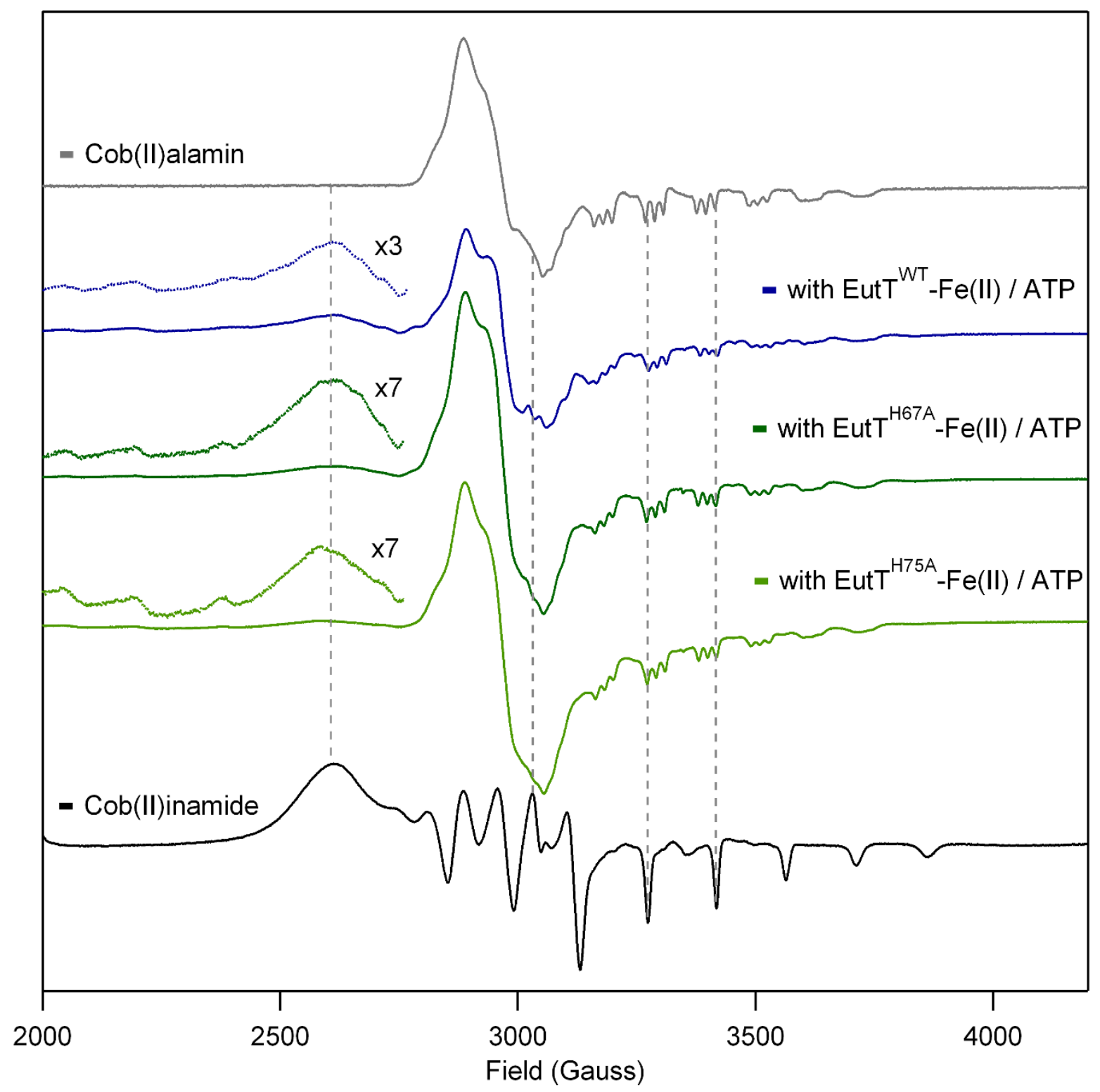

Figure S4. X-band EPR spectra collected at $40 \mathrm{~K}$ of $\mathrm{Co}(\mathrm{II}) \mathrm{Cbl}$ in the presence of Eut $\mathrm{T}^{\mathrm{WT}} / \mathrm{Fe}$ (blue), EutT ${ }^{\mathrm{H} 65 \mathrm{~A} / \mathrm{Fe}}$ (dark green), and Eut $\mathrm{T}^{\mathrm{H} 75 \mathrm{~A}} / \mathrm{Fe}$ (light green) with a >3-fold molar excess of MgATP. For reference, the spectrum of free $\mathrm{Co}(\mathrm{II}) \mathrm{Cbi}^{+}$(black) and free $\mathrm{Co}(\mathrm{II}) \mathrm{Cbl}$ (gray) are also shown. Primary features due to the base-off $\mathrm{Co}(\mathrm{II}) \mathrm{Cbl}$ species generated in the active site of EutT are highlighted by a dashed line. EPR spectra were collected using a 9.36 GHz microwave source, $2 \mathrm{~mW}$ microwave power, $5 \mathrm{G}$ modulation amplitude, $100 \mathrm{kHz}$ modulation frequency, and a $328 \mathrm{~ms}$ time constant. 


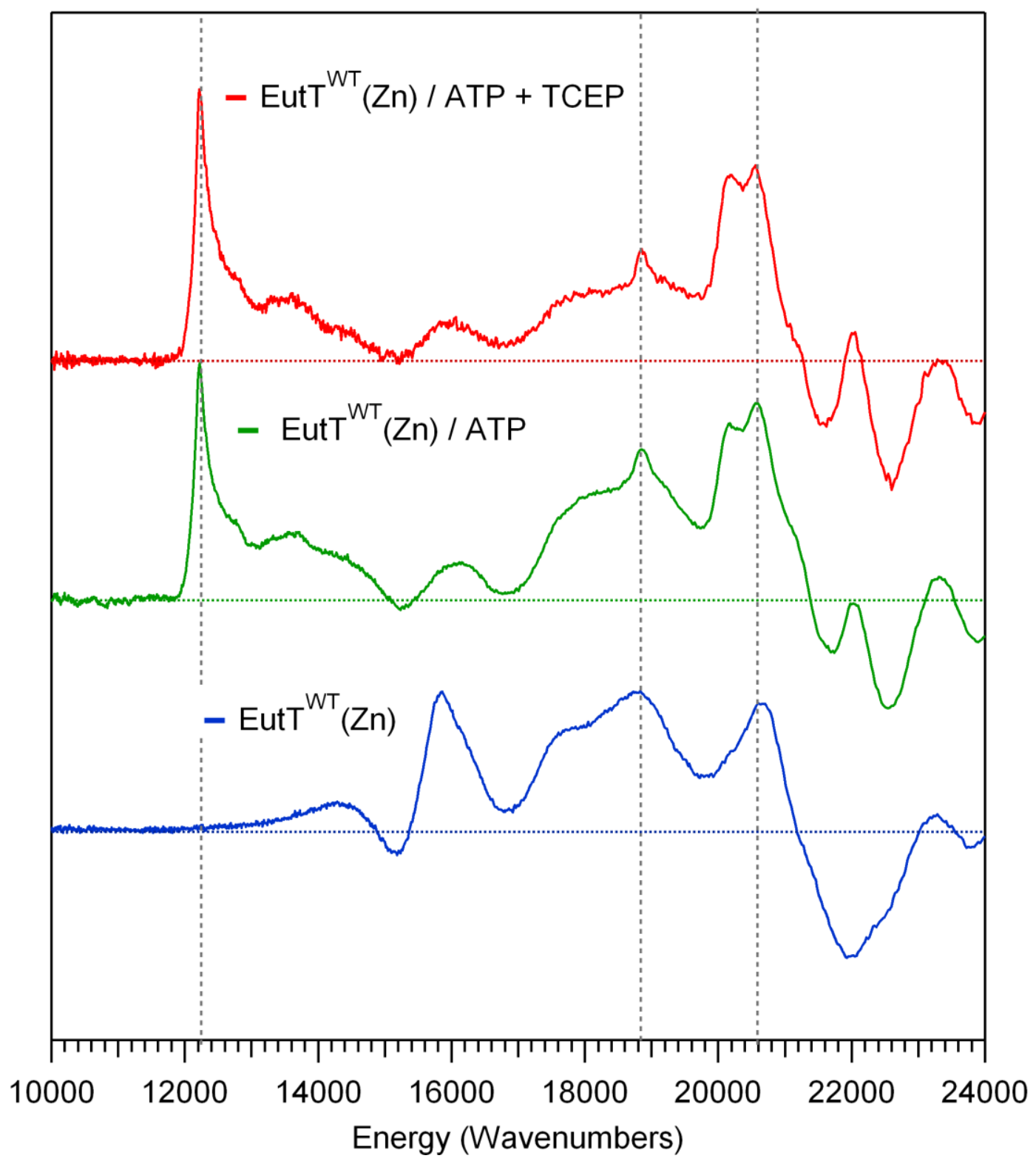

Figure S5. Low-temperature (4.5 K) MCD spectra of $\mathrm{Co}(\mathrm{II}) \mathrm{Cbl}$ obtained in the presence of EutT $^{\mathrm{WT}} / \mathrm{Zn}$ and (top) excess of MgATP and TCEP, (middle) excess of MgATP in the absence of TCEP, and (bottom) substoichiometric $\operatorname{MgATP}(<10 \mu \mathrm{M})$. The primary spectroscopic features due to $4 \mathrm{c} \mathrm{Co}(\mathrm{II}) \mathrm{Cbl}$ are labeled with vertical dashed lines. 


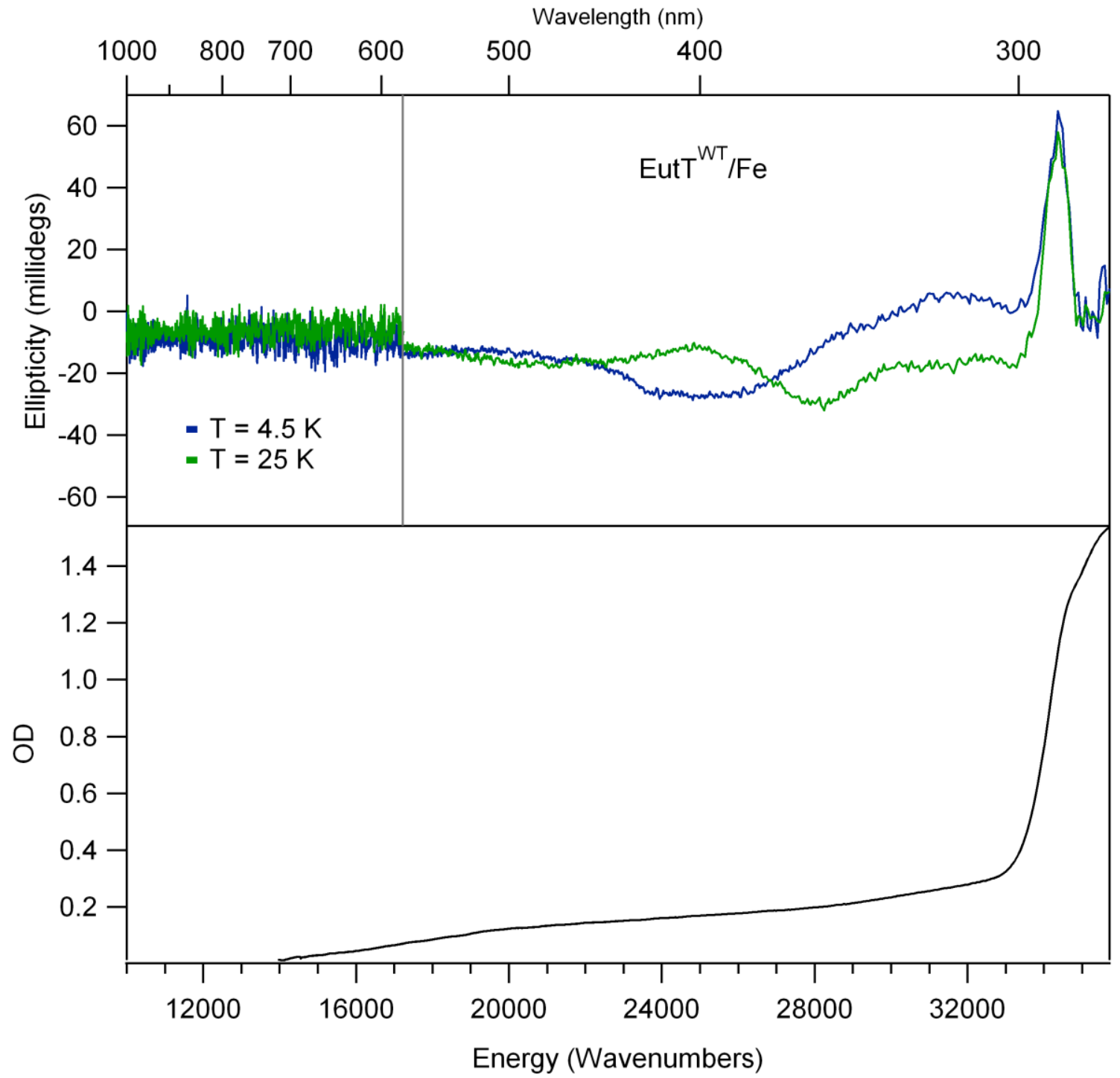

Figure S6. MCD (top) and 4.5 K Abs (bottom) spectra of Fe(II)-containing Eut $\mathrm{T}^{\mathrm{WT}}$ in the absence of substrates. 


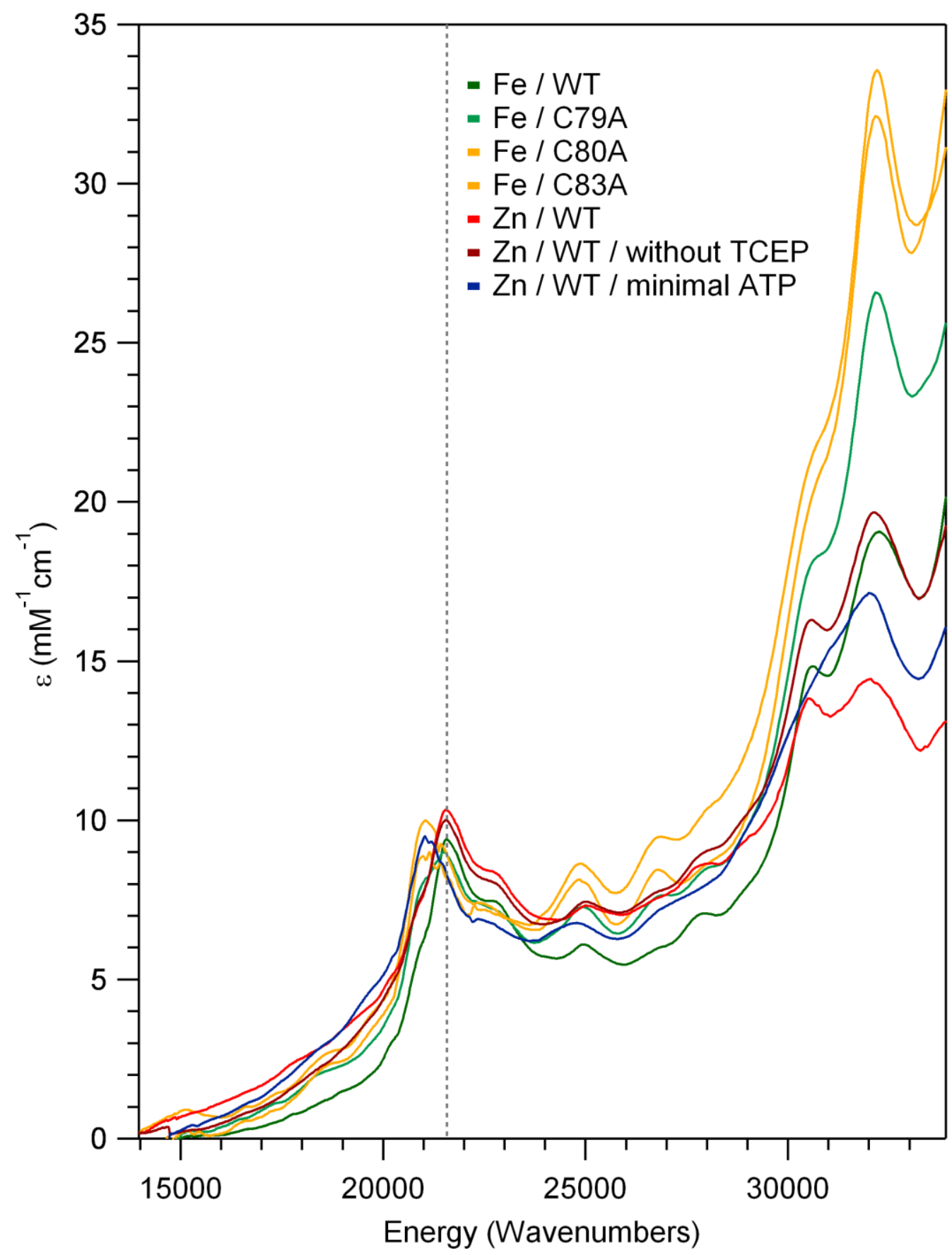

Figure S7. Low-temperature ( $4.5 \mathrm{~K})$ Abs spectra of $\mathrm{Co}(\mathrm{II}) \mathrm{Cbl}$ obtained in the presence of EutT $^{\mathrm{WT}} / \mathrm{Zn}$, EutT $\mathrm{T}^{\mathrm{WT}} / \mathrm{Fe}$, and selected variants under various conditions (with $>5 \mathrm{mM} \mathrm{MgATP}$ unless otherwise noted; minimal ATP corresponds to $\sim 7 \mu \mathrm{M}$ MgATP). The position of the $\alpha-$ band transition observed in the presence of $\mathrm{EutT}^{\mathrm{WT}} / \mathrm{Fe}$ and $\mathrm{MgATP}$ is highlighted by a dashed vertical line. 


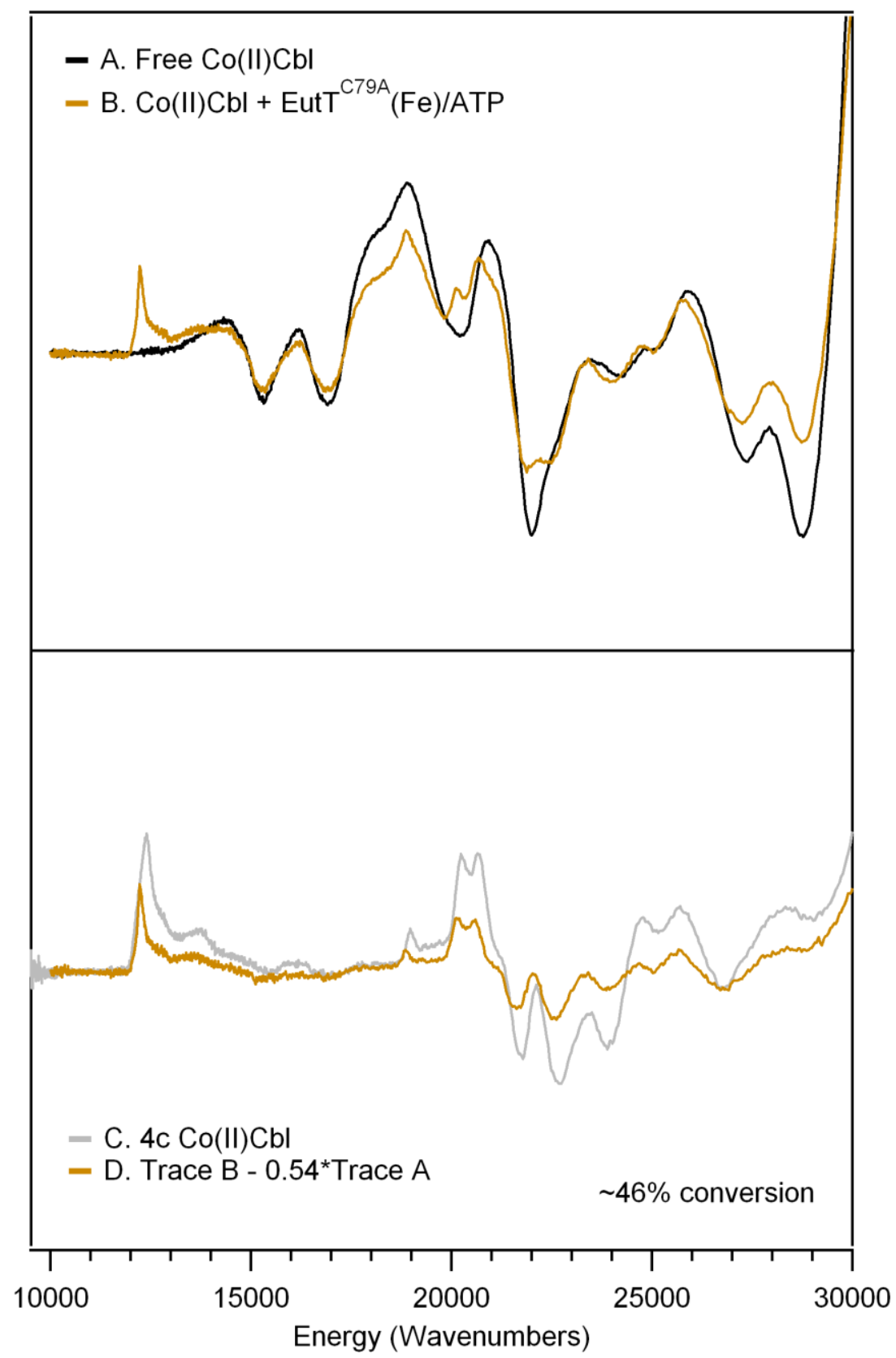

Figure S8. Deconvolution of the MCD spectrum of $\mathrm{Co}(\mathrm{II}) \mathrm{Cbl}$ obtained in the presence of EutT $^{\mathrm{C} 79 \mathrm{~A}} / \mathrm{Fe}$ and a $>10$-fold molar excess of $\operatorname{MgATP}(\mathrm{A})$. The spectrum of free $\mathrm{Co}(\mathrm{II}) \mathrm{Cbl}(\mathrm{B})$ was subtracted to yield the difference trace (D). The spectrum of EutT ${ }^{\mathrm{WT}} / \mathrm{Fe}$ and excess MgATP (C) is shown for comparison. 


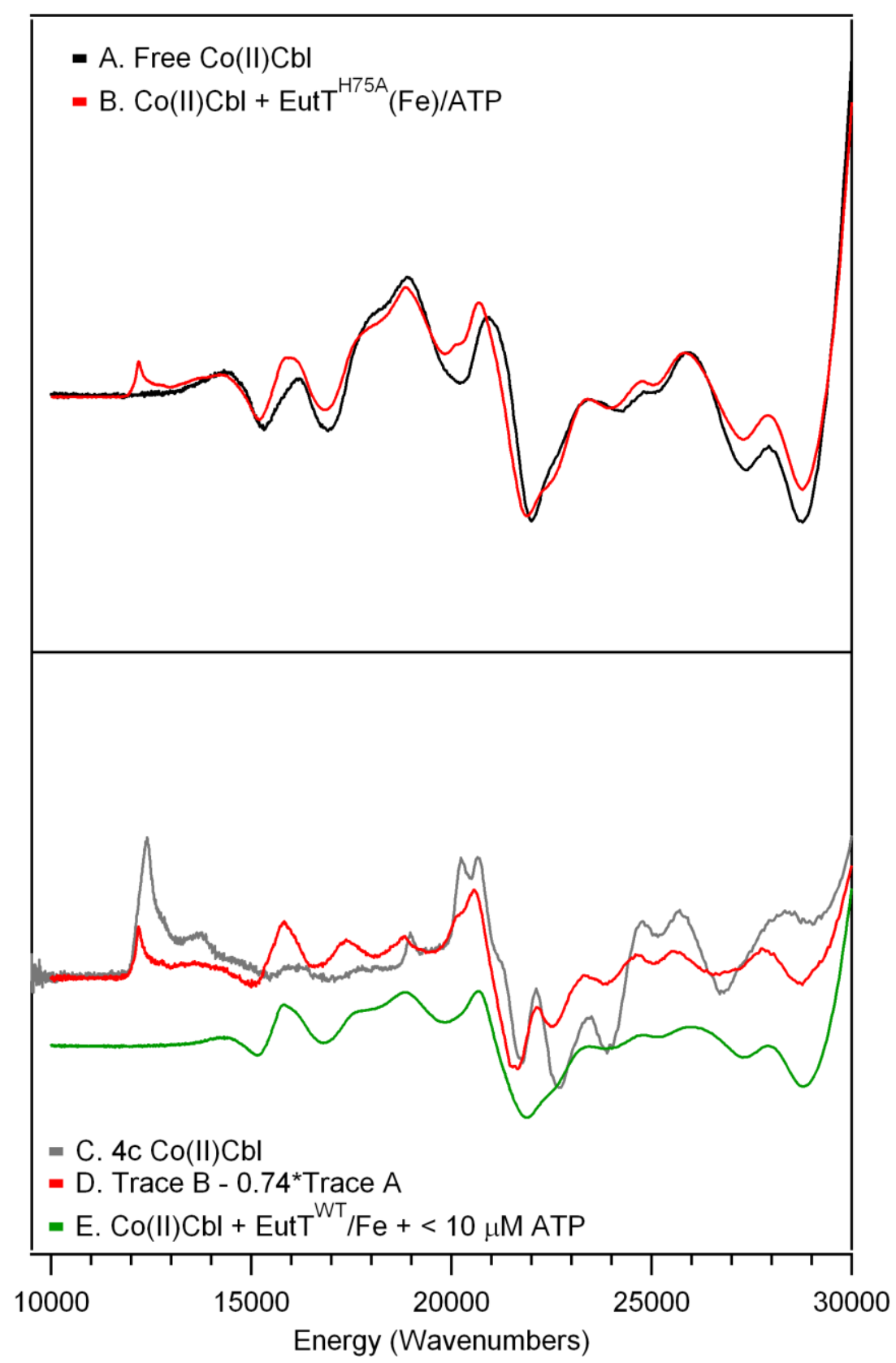

Figure S9. Deconvolution of the MCD spectrum of $\mathrm{Co}(\mathrm{II}) \mathrm{Cbl}$ obtained in the presence of EutT $^{\mathrm{H} 75 \mathrm{~A}} / \mathrm{Fe}$ and a 10-fold molar excess of $\operatorname{MgATP}(\mathrm{A})$. The spectrum of free $\mathrm{Co}(\mathrm{II}) \mathrm{Cbl}$ (B) was subtracted to yield the difference trace (D). The spectra of EutT ${ }^{\mathrm{WT}} / \mathrm{Fe}$ and excess $\mathrm{MgATP}(\mathrm{C})$ and of Eut $\mathrm{T}^{\mathrm{WT}} / \mathrm{Fe}$ and substoichiometric $(<10 \mu \mathrm{M})$ ATP are shown for comparison. 


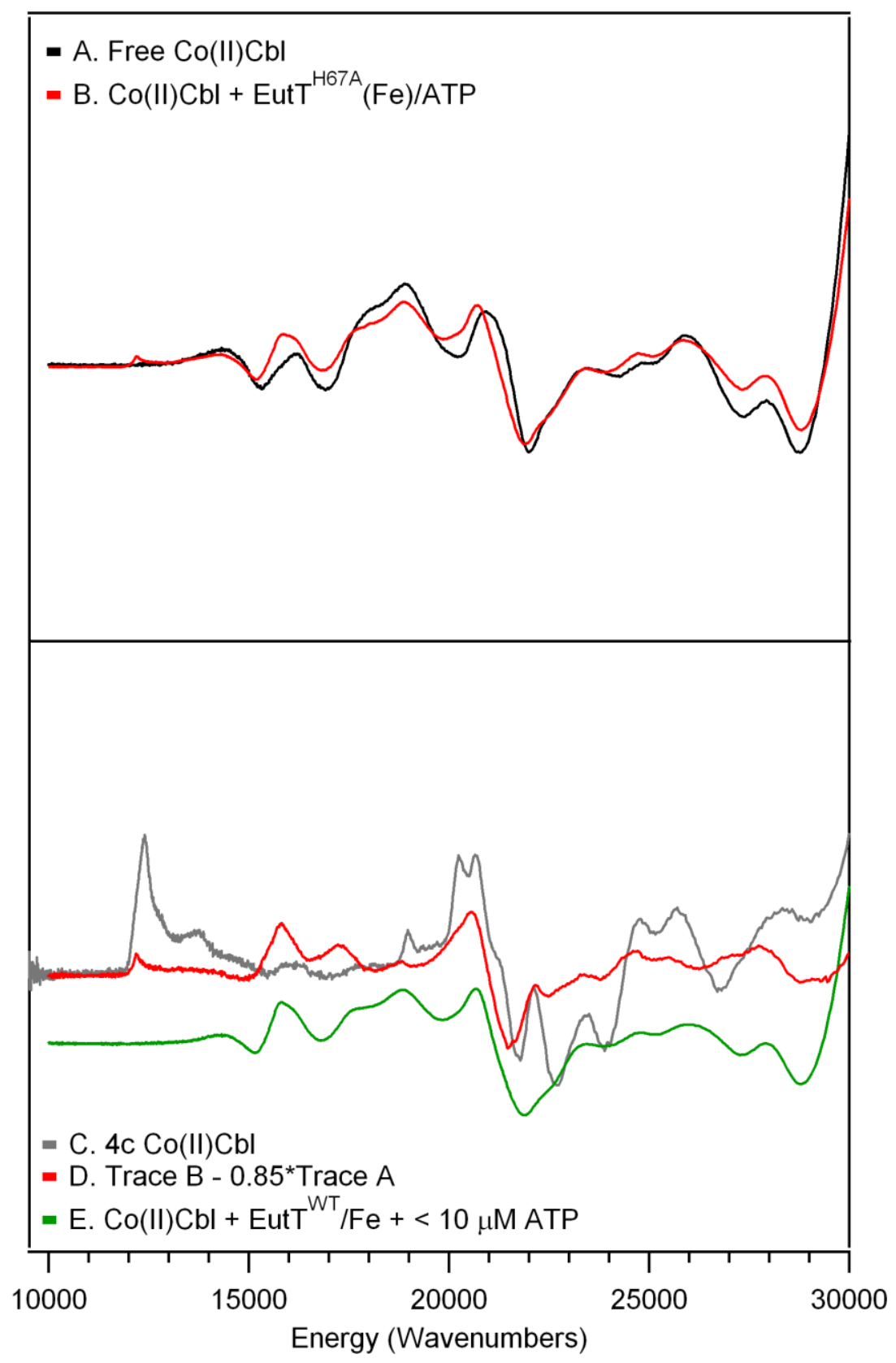

Figure S10. Deconvolution of the MCD spectrum of $\mathrm{Co}(\mathrm{II}) \mathrm{Cbl}$ obtained in the presence of EutT $^{\mathrm{H} 67 \mathrm{~A}} / \mathrm{Fe}$ and a $>10$-fold molar excess of $\operatorname{MgATP}(\mathrm{A})$. The spectrum of free $\mathrm{Co}(\mathrm{II}) \mathrm{Cbl}(\mathrm{B})$ was subtracted to yield the difference trace (D). The spectra of EutT ${ }^{\mathrm{WT}} / \mathrm{Fe}$ and excess $\mathrm{MgATP}$ (C) and of EutT ${ }^{\mathrm{WT}} / \mathrm{Fe}$ and substoichiometric $(<10 \mu \mathrm{M})$ ATP are shown for comparison. 